American Journal of Applied Sciences 5 (5): 586-596, 2008

ISSN 1546-9239

(C) 2008 Science Publications

\title{
Estimation of C*-Integral in Thin T-Sections Subjected to Projection and Remote Loading Base on Elastic Stress Concentration Factor
}

\author{
A.R. Gowhari-Anaraki, F. Djavanroodi and S. Shadlou \\ Department of Mechanical Engineering, Iran University of Science and Technology, Tehran, Iran
}

\begin{abstract}
The finite element method has been used to predict the creep rupture parameter, $\mathrm{C}^{*}$-Integral of flat T-section bar subjected to loaded projection and remote loading with a crack or crack-like flaw introduced in the fillet (i.e., high stress) region of the component. In this study, a new dimensionless creeping crack configuration factor, $\mathrm{Q}^{*}$ has been introduced. Power low creeping finite element analyses have been performed and the results are presented in the form of $\mathrm{Q}^{*}$ for a wide range of components and crack geometric parameters. These parameters are chosen to be representative of typical practical situations and have been determined from evidence presented in the open literature. The extensive range of $\mathrm{Q}^{*}$ obtained from the analyses are then used to obtain equivalent prediction equations using a statistical multiple non-linear regression model. The predictive equations for $\mathrm{Q}^{*}$, which are based on the elastic stress concentration factor, can also be used easily to calculate the $\mathrm{C}^{*}$-Integral values for extensive range of geometric parameters. The $\mathrm{C}^{*}$-Integral values obtained from predictive equations were also compared with those obtained from Reference Stress Method (RSM). Finally, creep zone growth behavior was studied in the component during transient time.
\end{abstract}

$\underline{\text { Key words: } \mathrm{C}^{*} \text {-Integral, loaded projections, loaded remotes, T-sections, creep zone, transition time }}$

\section{INTRODUCTION}

Projections on plates, bars and tubes are often used as a means of transmitting axial load between two components, e.g., T-shaped flat bars, shouldered plates/shafts/tubes, wide grooves, filleted transitions and many other geometric shapes with similar stress concentration features. For remote loading conditions, the point of application of the load is usually far removed from the region of stress concentration (Fig. 1a) and does not influence that local stress field. However, when the load or the reaction of the loading is applied at or near to the region of high stress gradient, such as for these 'loaded projections', the $\mathrm{C}^{*}$ Integral can be significantly higher than for the equivalent remote loading case (Fig. 1b). This is because there is both a tensile component and a bending component of load at the projection, as illustrated in Fig. 1c. Crack failure is a major consideration in mechanical design. Nearly all crack failures initiate at stress concentration features, i.e. at the point of highest stress. In general, the initial crack (or any crack like flaw, void, defect, etc.) will develop in three stages, as presented in reference ${ }^{[1]}$, namely initiation, propagation and fracture. Crack initiation is analyzed at the microscopic level, while for crack propagation the continuum mechanics approach based on a macroscopic scale is used. The rupture fracture parameters in a remotely loaded cracked component is controlled by the notch radius, $r$, plate length, 1 , crack length, a and the remotely applied load, P, as shown in Fig. 1a, for cracked components with loaded projections the projection length, $\mathrm{h}$ and the combined effect of tensile and bending loading also affect the $\mathrm{C}^{*}$-Integral or any fracture parameters, as illustrated in Fig. $1 \mathrm{~b}$ and c.

In order to predict the strength of the cracked component, the crack growth rate and the critical crack size, in high temperature situation, an accurate value for $\mathrm{C}^{*}$-Integral along the crack front has to be known. Many experimental, numerical and analytical solutions for the three basic stress intensity factors $\mathrm{K}_{\mathrm{i}}(\mathrm{i}=\mathrm{I}$, II, III) have been deduced for varying crack sizes for relatively simplistic structures with simple loading conditions. Paris and $\mathrm{Sih}^{[2]}$ present a comprehensive handbook of such results.

In addition, crack tip stress fields have previously been studied and data on elastic stress intensity factors are readily available ${ }^{[3]}$. Also, the crack tip stress solution for flanked notches ${ }^{[4]}$. J-Integral and stress concentration factor for $\mathrm{T}$-sections were also reported ${ }^{[5]}$.

However, in a high temperature situation with time the stress in the vicinity of the crack begins to relax due to creep deformation and the size of the relaxation (or creep) zone increases with time if the crack is assumed

Corresponding Author: F. Djavanroodi, Department of Mechanical Engineering, Iran University of Science and Technology, Tehran, Iran 


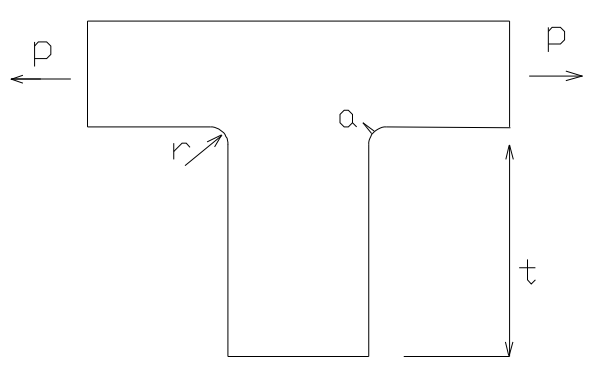

(a) 'Remotely' loaded cracked component

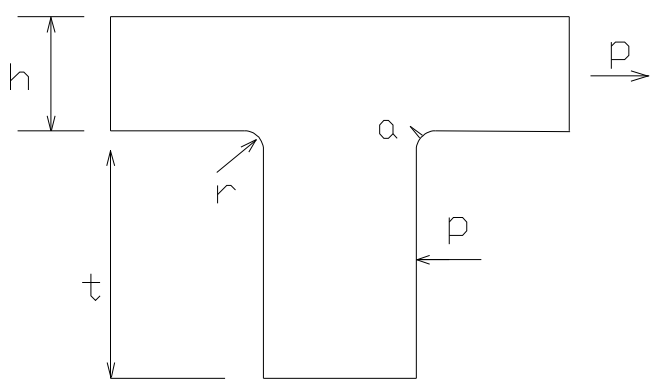

(b) Cracked component with loaded projection and

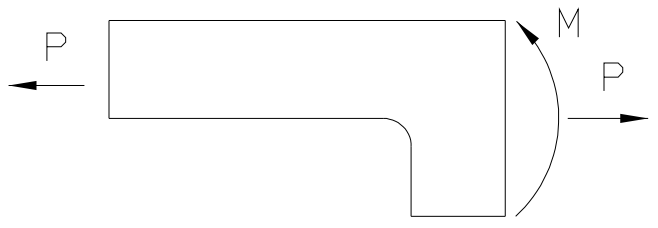

(c) Tension and bending effects associated with loaded projections

Fig. 1: Typical example of a loaded projection and remote loading

to remain stationary. Neither $\mathrm{K}$ nor J-Integral is expected to uniquely characterize the crack tip stress relaxation (or redistribution) behavior within the creep zone because creep deformation is not admitted in their formulation. So using $\mathrm{C}^{*}$-Integral in creep situation were recommended.

To simplify the estimation of $\mathrm{C}^{*}$-Integral in different components many ways have been recommended. For example determination of fracture mechanics parameters $\mathbf{J}$ and $\mathrm{C}^{*}$ by finite element and reference stress methods for a semi-elliptical flaw in a plate were reported ${ }^{[6]}$. Also relevance of plastic limit loads to reference stress approach for surface cracked cylinder problems were reported ${ }^{[7]}$. In addition, creep crack initiation and creep crack growth assessments in welded structures have been studied ${ }^{[8]}$. All previously published papers for estimation of the $\mathrm{C}^{*}$-Integral values are based on reference stress or limit load approaches. These methods are known as "simplified methods", which are able to estimate the $\mathrm{C}^{*}$-Integral values very conservatively. These methods should also be supported by a finite element analysis in order to calculate the reference stress or limit load value. However, in this study by the analogy with the JIntegral, a new relation for the $\mathrm{C}^{*}$-Integral has been suggested. For this purpose, a new dimensionless creeping crack configuration factor, $Q^{*}$, has been defined in analogy with fracture crack configuration factor, Q, as follows:

$$
\begin{gathered}
J=f\left(Q, \sigma_{0}, a, E\right) \\
C^{*}=f\left(Q^{*}, \sigma_{0}, a, n\right)
\end{gathered}
$$

Where $\sigma_{0}$ and a are nominal stress and crack length, respectively. E and $\mathrm{n}$ are material modulus of elasticity and material creep properties, respetively.

In this study at first linear elastic finite element analyses have been performed and elastic stress concentration factor obtained for a wide range of components without crack. Then power low creeping finite element analyses have been performed and the result are presented in the form of $\mathrm{Q}^{*}$ for a wide range of components, having different stress concentration factors, crack lengths and material creep properties at different temperature. The extensive range of elastic stress concentration factors and $\mathrm{Q}^{*}$ obtained from the FE analysis for different crack lengths and material creep properties, are then used to obtain equivalent prediction equations using a statistical multiple nonlinear regression model ${ }^{[9]}$. The accuracy of this model is measured using a multiple coefficient of determination, $\mathrm{R}^{2}$ where $0 \leq \mathrm{R}^{2} \leq 1$. This coefficient is found to be greater than or equal to 0.98 for all cases considered in this study, demonstrating the quality of the model fit to the data. These equations can be used to obtain $\mathrm{C}^{*}$ values that are based on the elastic stress concentration factor for the geometries and material properties being considered. Thus, a direct link is provided between the stress concentration factor (which can be easily determined either from the predictive equations presented here or via elastic finite element analysis) and $\mathrm{C}^{*}$-Integral, which normally require the use of complicated power low creeping fracture mechanics analysis.

\section{GEOMETRY, LOADING AND BOUNDARY CONDITIONS}

For loaded projection conditions four dimensions are used to define the geometry, as shown in Fig. 2. They are the projection length, h, the projection width, 


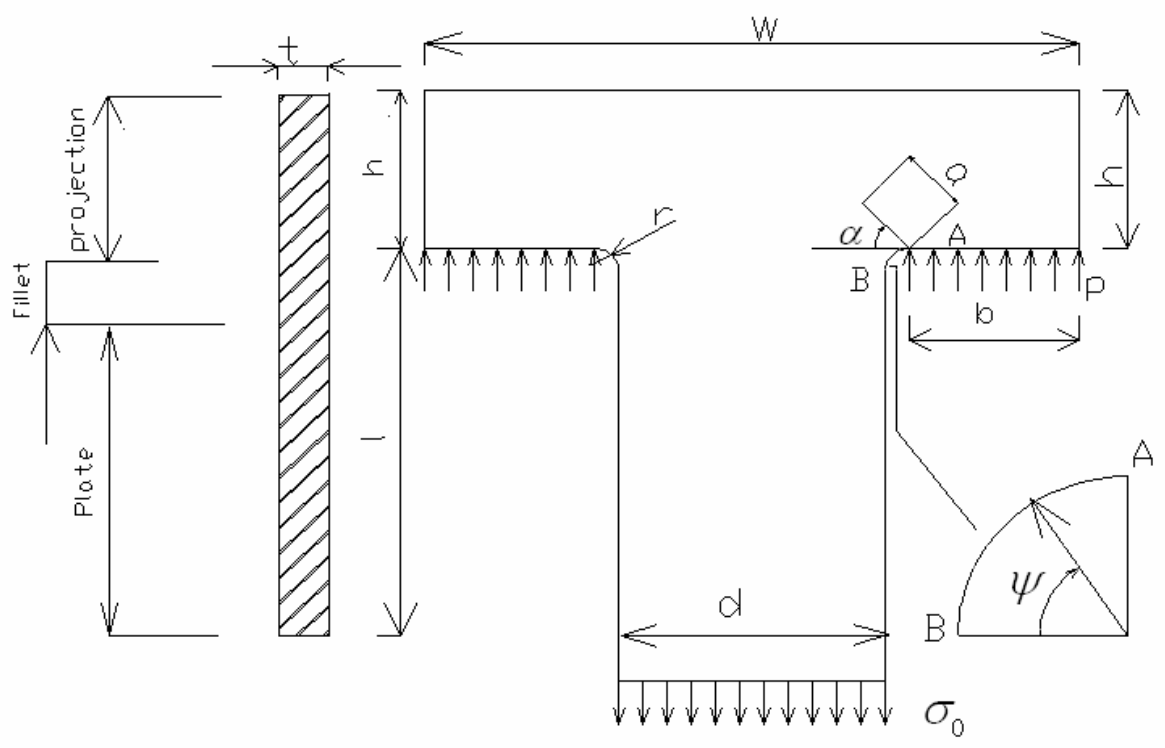

Fig. 2: Component geometry with loaded projection condition

$\mathrm{w}$, the plate width, $\mathrm{d}$ and the fillet radius, $\mathrm{r}$. Three nondimensional parameters are formed by normalizing with respect to the plate width, d, i.e. $\mathrm{h} / \mathrm{d}$, w/d and $\mathrm{r} / \mathrm{d}$.

The range of dimensions selected for the parametric study is consistent with the geometric cases covered by Engineering Sciences Data Unit (ESDU) data item $69020^{[10]}$ and is considered to present a range of practical interest. The selected ranges

$$
\begin{aligned}
& 0.5 \leq \frac{\mathrm{h}}{\mathrm{d}} \leq 3 \\
& 1.5 \leq \frac{\mathrm{w}}{\mathrm{d}} \leq 3 \\
& 0.05 \leq \frac{\mathrm{r}}{\mathrm{d}} \leq 0.2
\end{aligned}
$$

The plate length, $\mathrm{L}$, is long enough to ensure that uniform stress distribution is achieved away from the fillet. A plane stress assumption (i.e., thin plate) is made for all geometries considered.

In remote loading, the loading condition consists of a remotely applied axial stress, $\sigma_{0}$, reacted by a uniform pressure, $\mathrm{P}$, across the entire upper section of the projection as shown in Fig. 3. The loaded projection condition consists of a remotely applied axial stress, $\sigma_{0}$, reacted by a uniform pressure, $\mathrm{P}$, across the entire flat section of the shoulder as shown in Fig. 2. The flat section of the shoulder has a width, $b$, where

$$
\mathrm{b}=\frac{1}{2}(\mathrm{w}-\mathrm{d})-\mathrm{r}
$$

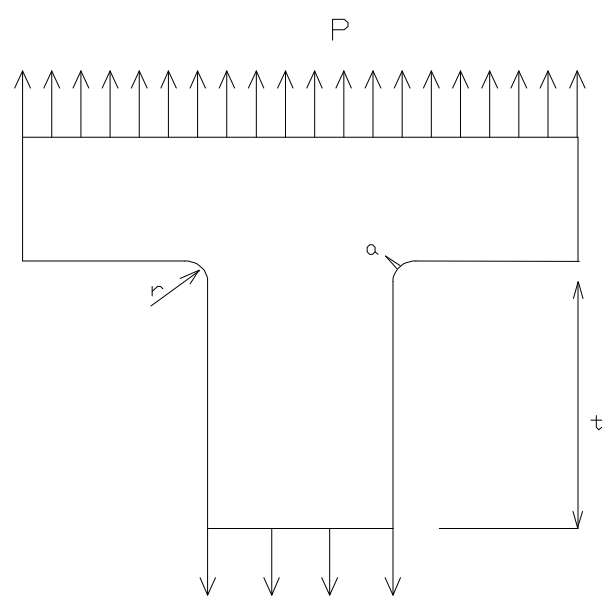

Fig. 3: Component geometry with remote loading condition by

In addition, the nominal stress in the plate is given

$$
\sigma_{0}=\frac{2 \mathrm{pb}}{\mathrm{d}}=\mathrm{p}\left(\frac{\mathrm{w}}{\mathrm{d}}-2 \frac{\mathrm{r}}{\mathrm{d}}-1\right)
$$

The nominal stress, $\sigma_{0}$, for remote loading condition can be written as:

$$
\sigma_{0}=\mathrm{p} \frac{\mathrm{w}}{\mathrm{d}}
$$


A range of crack lengths, a, is considered on the basis of the observations of surface cracks in fractured standard NDT (nondestructive testing) test specimens $^{[11]}$, i.e., $\mathrm{a}=0.5-2.5 \mathrm{~mm}$. Many engineering components contain, or are assumed to contain, such cracks for life assessment purposes at the design stage. Such cracks may grow owing to fatigue, corrosion, creep, etc.

\section{FINITE ELEMENT ANALYSIS OF THE CRACKED COMPONENTS}

Finite element predictions have been obtained using the Power law creeping fracture mechanics facilities within the ABAQUS ${ }^{[12]}$ suite of programs. Six- and eight-noded, reduced integration, plane stress, triangular and quadrilateral elements were used with the crack tip singularity represented by collapsing one side of a quadrilateral to form a triangular element so that there are three points in crack tip.

A typical finite element mesh is shown in Fig. 4. Due to lack of creep crack study in T-section component at first, some elastic finite element analyses have been done and the results were compared with data available $e^{[5]}$.

This comparison confirmed that the level of mesh refinement and the use of the crack tip elements in current study would provide accuracy to within $\pm 3 \%$.

Values for Young's modulus, density and Poisson's ratio of $209 \mathrm{GPa}, 7840 \mathrm{~kg} \mathrm{~m}^{-3}$ and 0.3 , respectively has been used throughout the analysis. In creep situation, Strain was assumed to obey Bailey-Norton creep law.

Table 1: Material creep properties and rupture stress for rene 80

\begin{tabular}{llll}
\hline 1150 & 930 & 650 & $\mathrm{~T}\left({ }^{\circ} \mathrm{C}\right)$ \\
\hline $16.272 \times 10^{-} 3$ & $6.37 \times 10^{-} 5$ & $1.855 \times 10^{-} 6$ & $\mathrm{~A}\left(\frac{1}{(\mathrm{Mpa})^{n} \mathrm{hr}}\right)$ \\
1.43 & & & $\mathrm{n}$ \\
165 & 4.6 & 2.54 & $\sigma_{\mathrm{R}}(\mathrm{Mpa})$ \\
\hline
\end{tabular}

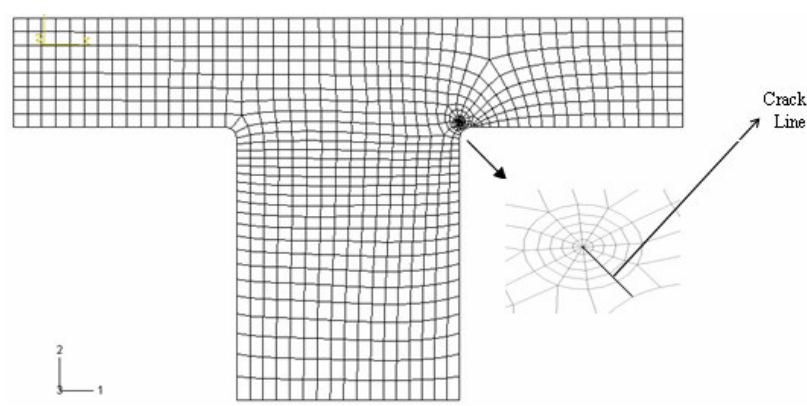

Fig. 4: Typical finite element mesh

$$
\dot{\varepsilon}=A \sigma^{\mathrm{n}}
$$

The material creep properties for rene 80, are listed in Table 1.

\section{RESULTS}

$C^{*}$-Integral values: The $C^{*}$-Integral values have been obtained using a numerical procedure based on the Virtual Crack Extension Method (VCEM) suggested by Landes and Begley ${ }^{[13]}$, as follows:

$$
C^{*}=\int_{\Gamma}^{0} w^{*} d y-T_{i}\left(\frac{\partial \dot{u}_{i}}{\partial x}\right) d s
$$

Where

$$
\mathrm{W}^{*}=\int_{0}^{\dot{\varepsilon}_{\mathrm{y}}} \sigma_{\mathrm{ij}} \mathrm{d} \dot{\varepsilon}_{\mathrm{ij}}
$$

$\Gamma$ is a line contour shown in Fig. 5 taken counterclockwise from the lower crack surface to the upper crack surface. $W^{*}$ is the strain energy rate density associated with the point stress, $\sigma_{\mathrm{ij}}$ and strain rate $\dot{\varepsilon}_{\mathrm{ij}}$. $\mathrm{T}_{\mathrm{i}}$ is the traction vector defined by the outward normal, $n_{j}$, along $\Gamma$.

Here, the VCEM procedure incorporated in the $\mathrm{ABAQUS}^{[12]}$ finite element program has been used to calculate the $C^{*}$-Integral values. It has been shown in ${ }^{[14]}$ that the value of $C^{*}$ is independent of the path $\Gamma$ if the path originates at any point on the lower crack surface and goes counter clockwise and ends at any point on the upper crack surface.

In order to validate FEM predictions, $\mathrm{C}^{*}$-Integral values have been obtained using three separate contours around the crack tip, which are shown in Fig. 5 for a typical geometry. All contour integrals generally showed good path independence, as illustrated in

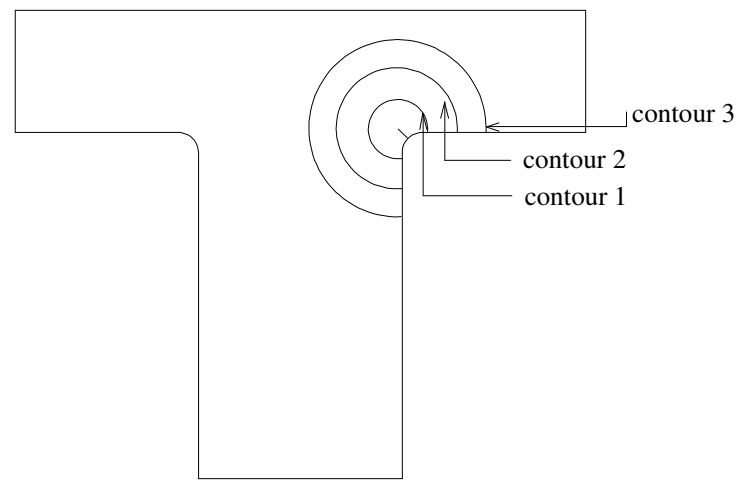

Fig. 5: C*-Integral contour paths 
Am. J. Applied Sci., 5 (5): 586-596, 2008

Table 2: Normalized $\mathrm{C}^{*}$-Integrals for typical contour paths

\begin{tabular}{llll}
\hline 1 & 2 & 3 & Contour \\
\hline 0.986 & 0.995 & 1 & $C^{*}$ Normalized \\
\hline
\end{tabular}

Table 2 where the $\mathrm{C}^{*}$ values are normalized with respect to the value for the outermost contour 3 . Consequently, the values for contour 3 were used throughout this study.

Stress concentration factor: The elastic stress concentration factor is defined as a geometric correction factor, which is a function of three nondimensional parameters $\mathrm{h} / \mathrm{d}$, w/d and $\mathrm{r} / \mathrm{d}$, as follows:

$$
\mathrm{K}_{\mathrm{t}}=\mathrm{f}\left(\frac{\mathrm{h}}{\mathrm{d}}, \frac{\mathrm{w}}{\mathrm{d}}, \frac{\mathrm{r}}{\mathrm{d}}\right)
$$

To determined stress concentration factor $\mathrm{K}_{\mathrm{t}}$ in a $\mathrm{T}$-section component subjected to loaded projection the following relation ship was reported ${ }^{[5]}$, using a statistical multiple nonlinear regression model:

$$
\begin{aligned}
& 0.91(\mathrm{~h} / \mathrm{d})^{2.11}+0.26(\mathrm{w} / \mathrm{d})^{1.44}- \\
& \mathrm{k}_{\mathrm{t}}=\frac{0.57(\mathrm{r} / \mathrm{d})^{0.92}+0.14}{(\mathrm{~h} / \mathrm{d})^{1.68}(\mathrm{w} / \mathrm{d})^{0.25}(\mathrm{r} / \mathrm{d})^{0.49}}
\end{aligned}
$$

In a similar way to ${ }^{[5]}$, the following equation is derived for the stress concentration factor of a T-section component under remote loading condition:

$$
\mathrm{k}_{\mathrm{t}}=\frac{0.842+1.06 \times\left(\frac{\mathrm{w}}{\mathrm{d}}\right)^{1.517}+0.941 \times\left(\frac{\mathrm{r}}{\mathrm{d}}\right)^{1.083}}{1.083 \times\left(\frac{\mathrm{w}}{\mathrm{d}}\right)^{0.383}+1.164 \times\left(\frac{\mathrm{r}}{\mathrm{d}}\right)^{0.758}}
$$

The accuracy of this equation has been assessed using a multiple coefficient of determination ${ }^{[9]}, \mathrm{R}^{2}$, where $0 \leq R^{2} \leq 1$. This coefficient was found to be approximately 0.984 , which demonstrates the accuracy of model fit to the data. As it is evident the projection length, h, does not appear in Eq. 11 so it does not effect $\mathrm{k}_{\mathrm{t}}\left(\right.$ or $\left.\mathrm{C}^{*}\right)$.

Crack location and inclination: Five components under remote and projection loading have been considered in this study that are shown in Table 3 and 4 for loaded projection and remote loading. $\mathrm{k}_{\mathrm{t}}$ changes for these components from minimum to maximum amount. $\mathrm{FE}$ analysis have shown that the maximum $\mathrm{C}^{*}$-Integral value, depending of the geometry and loading condition, corresponded to a crack emanating from a point around the fillet $\Psi_{\max }$, as shown in Fig. 2 and Table 3, 4 .

Table 3: Geometries used in loaded projection condition

\begin{tabular}{lcccccc}
\hline$\alpha_{\max }$ & $\psi_{\max }$ & $\mathrm{k}_{\mathrm{t}}$ & $\frac{\mathrm{w}}{\mathrm{d}}$ & $\frac{\mathrm{h}}{\mathrm{d}}$ & $\frac{\mathrm{r}}{\mathrm{d}}$ & Geometry No. \\
\hline 30 & 30 & 2.78 & 0.20 & 3.0 & 3.00 & 1 \\
55 & 55 & 7.29 & 0.07 & 2.7 & 0.80 & 2 \\
55 & 55 & 10.46 & 0.09 & 2.5 & 0.50 & 3 \\
55 & 55 & 13.54 & 0.06 & 2.8 & 0.52 & 4 \\
55 & 55 & 16.69 & 0.05 & 3.0 & 0.50 & 5 \\
\hline
\end{tabular}

Table 4: Geometries used in remote loading condition

\begin{tabular}{lccccc}
\hline$\alpha_{\max }$ & $\psi_{\max }$ & $\mathrm{k}_{\mathrm{t}}$ & $\frac{\mathrm{r}}{\mathrm{d}}$ & $\frac{\mathrm{w}}{\mathrm{d}}$ & Geometry No. \\
\hline 0 & 20 & 1.84 & 0.2 & 1.5 & 1 \\
55 & 27 & 2.99 & 0.09 & 2.5 & 2 \\
55 & 20 & 3.26 & 0.07 & 2.7 & 3 \\
60 & 30 & 3.41 & 0.06 & 2.8 & 4 \\
60 & 45 & 3.67 & 0.05 & 3.0 & 5 \\
\hline
\end{tabular}

Also to determine the inclination of the crack to the transverse direction $\alpha$, maximum, $C^{*}$ values in different directions were calculated and the results are shown in Table 3 and 4.

Figure 6 and 7 show variation in $C^{*}$-integral with direction of crack for projection and remote loading respectively. In projection loading condition the results show that in the range of $40^{\circ}<\alpha 70^{\circ} \mathrm{C}^{*}$ values are very close together and variation in $\alpha$ does not have an important effect on $C^{*}$ values. and for $20^{\circ}<\alpha<90^{\circ}$ maximum error is about $25 \%$.

In remote condition the results show that in the range of $0^{\circ}<\alpha<90^{\circ}$ maximum error is about $28 \%$. It is clear from above results that considering a constant direction of crack are conservative and useful for other directions of crack under any loading condition.

\section{Analytical equation for $\mathbf{C} *$-Integral:}

The J-Integral is usually written as:

$$
\mathrm{J}=\frac{\mathrm{K}_{\mathrm{I}}^{2}}{\mathrm{E}}
$$

Where

$$
\mathrm{K}_{\mathrm{I}}=\mathrm{F}_{\mathrm{C}} \sigma_{0} \sqrt{\pi \mathrm{a}}
$$

Where $F_{C}$ is the crack configuration factor that is function of geometry. Substitution of Eq. 13 into 12 gives:

$$
\mathrm{J}=\frac{\mathrm{F}_{\mathrm{c}}^{2} \pi}{\mathrm{E}} \sigma_{0}^{2} \mathrm{a}
$$

Or in a simple form:

$$
\mathrm{J}=\mathrm{Q} \sigma_{0}^{2} \mathrm{a}
$$




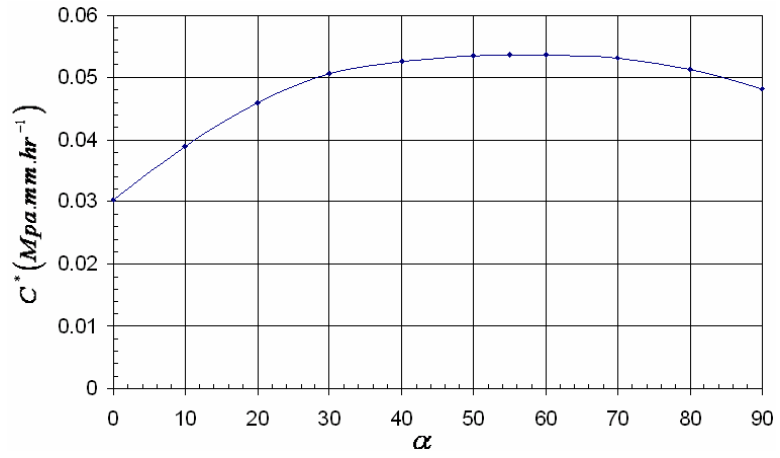

Fig. 6: Variation in $\mathrm{C}^{*}$-integral with direction of crack for projection loading Geometry No. 5. $\mathrm{A}=0.5 \mathrm{~mm}, \mathrm{~d}=20 \mathrm{~mm}, \mathrm{~T}=1150^{\circ} \mathrm{C}$

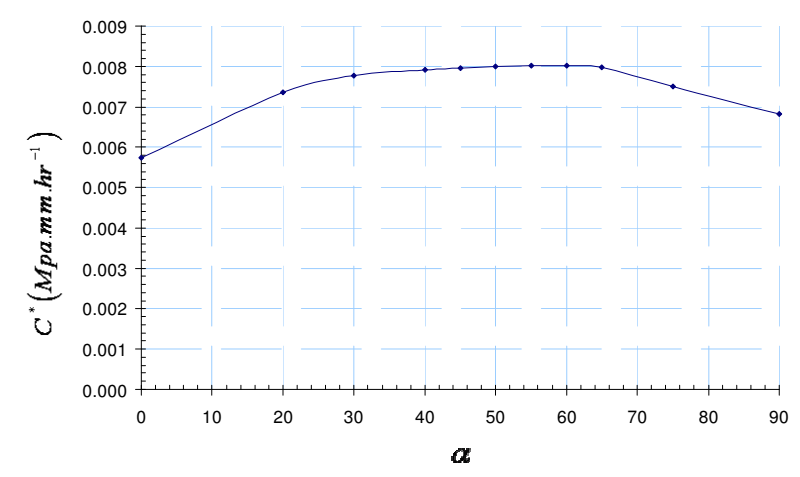

Fig. 7: Variation in $\mathrm{C}^{*}$-integral with direction of crack for remote loading Geometry No. $4 \mathrm{a}=0.5 \mathrm{~mm}$, $\mathrm{d}=20 \mathrm{~mm}, \mathrm{~T}=1150^{\circ} \mathrm{C}$

Where $\mathrm{Q}$ is called fracture configuration factor. A similar equation for $\mathrm{C}^{*}$-Integral has been proposed. It was consider that the relation between $\mathrm{C}^{*}$ and nominal stress in creep range is not linear. Keeping all the parameters constant and changing the values of nominal stress, it has been shown that the relation between $\mathrm{C}^{*}$ and nominal stress as follows:

$$
\mathrm{C}^{*} \propto \sigma_{0}^{\mathrm{n}+1}
$$

Where $\mathrm{n}$ is creep exponent. Therefore the relation between $\mathrm{C}^{*}$ and nominal stress depends on creep behavior of material.

By the analogy with the stress intensity factor and considering the above relation, the following equation for $\mathrm{C}^{*}$ has been defined as:

$$
\mathrm{C}^{*}=\frac{\mathrm{Q}^{*} \sigma_{0} \mathrm{a}}{\mathrm{t}_{\mathrm{T}}}\left(\frac{\sigma_{0}}{0.001 \times \sigma_{\mathrm{R}}}\right)^{\mathrm{n}}
$$

Where, $\mathrm{Q}^{*}$ is a non-dimensional parameter which is function of geometry and creep behavior of material and $\sigma_{0}$ is nominal stress, $\sigma_{\mathrm{R}}$ is rupture stress of material, $\mathrm{t}_{\mathrm{T}}$ is transition time and $\mathrm{a}$ is crack length.

In this study the average rupture stress $\left(\sigma_{\mathrm{R}}=170\right.$ $\mathrm{MPa})$ and transition time $\left(\mathrm{t}_{\mathrm{T}}\right)$ equal $1000 \mathrm{~h}$ has been used for the analysis. Using $\mathrm{C}^{*}$-Integral values $\mathrm{Q}^{*}$ values have been obtained using Eq. 17 (i.e., normalizing). Using statistical multiple non-linear regression, to obtain a more accurate equation, the data were divided into 2 section based on material creep properties. In projection loading $\mathrm{Q}^{*}$ for $1.43 \leq \mathrm{n}<2.54$ are defined as:

$$
\begin{aligned}
\mathrm{Q}^{*}= & \frac{1.749+0.720 \times\left(\frac{\mathrm{a}}{\mathrm{d}}\right)^{0.898} \times\left(\mathrm{k}_{\mathrm{t}}\right)^{2.343}}{\left(11.979 \times\left(\frac{\mathrm{a}}{\mathrm{d}}\right)^{0.898}+1.638 \times\left(\mathrm{k}_{\mathrm{t}}\right)^{1.057}\right)} \\
& \frac{\left(\mathrm{n}^{-3.894}-2.587 \times 10^{-2}\right)}{\left(\mathrm{n}^{2.027}-2.011\right)}
\end{aligned}
$$

The accuracy of Eq. 18 has been measured by means of a multiple coefficient of determination, $\mathrm{R}^{2}$, where $0 \leq R^{2} \leq 1$, this coefficient was found to be $R^{2}=$ 0.992 .

For projection loading and $2.54 \leq \mathrm{n} \leq 4.6 \mathrm{Q}^{*}$ is defined as:

$$
\begin{aligned}
Q^{*}= & \frac{15.717 \times 10^{-3}+3.606 \times 10^{-7}\left(\frac{\mathrm{a}}{\mathrm{d}}\right)^{-0.547}\left(\mathrm{k}_{\mathrm{t}}\right)^{4.163}}{\left(-1.331 \times 10^{-2}\left(\frac{\mathrm{a}}{\mathrm{d}}\right)^{1.277}+2.366\left(\mathrm{k}_{\mathrm{t}}\right)^{-2.682}\right)} \\
& \frac{\left(\mathrm{n}^{1.096}-2.766\right)}{\left(\mathrm{n}^{2.295}+0.797\right)}
\end{aligned}
$$

Multiple coefficient of determination was found to be $\mathrm{R}^{2}=0.989$ for this equation.

In remote loading $\mathrm{Q}^{*}$ for $1.43 \leq \mathrm{n}<2.54$ are defined as:

$$
\mathrm{Q}^{*}=\frac{4.783 \times 10^{-5}\left(\mathrm{k}_{\mathrm{t}}\right)^{10.814}}{\left(\frac{\mathrm{a}}{\mathrm{d}}\right)^{0.530}} \frac{\left(\mathrm{n}^{-3.486}-3.757 \times 10^{-2}\right)}{\left(\mathrm{n}^{2.352}-2.191\right)}
$$

Multiple coefficient of determination was found to be $\mathrm{R}^{2}=0.98$ for this equation. $\mathrm{Q}^{*}$ for $2.54 \leq \mathrm{n} \leq 4.6$ are defined as:

$$
\mathrm{Q}^{*}=\frac{2.108 \times 10^{-12}\left(\mathrm{k}_{\mathrm{t}}\right)^{23.29}}{\left(\frac{\mathrm{a}}{\mathrm{d}}\right)^{0.427}} \frac{\left(\mathrm{n}^{1.15}-2.906\right)}{\left(\mathrm{n}^{3.363}+3.77\right)}
$$




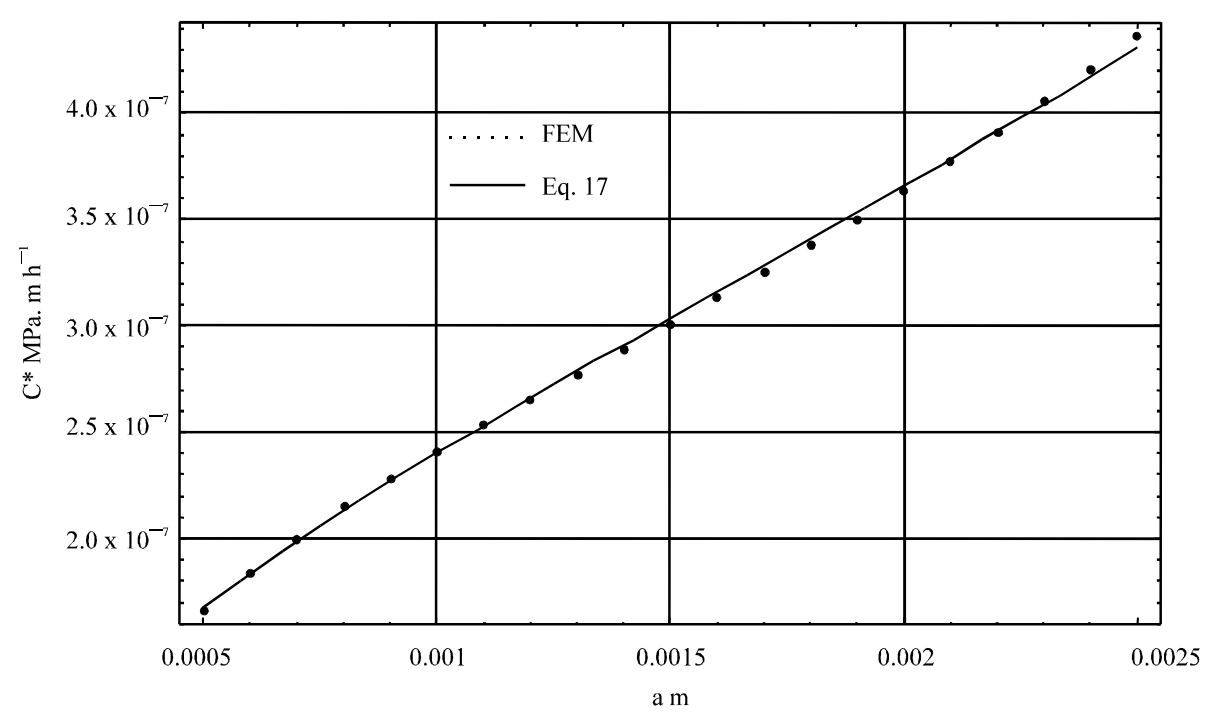

Fig. 8: Variation in $\mathrm{C}^{*}$-integral with crack length for loaded projection Geometry No. $5 \mathrm{~d}=60 \mathrm{~mm}, \mathrm{~T}=930^{\circ} \mathrm{C}, \sigma_{0}=$ $0.1 \mathrm{Mpa}$

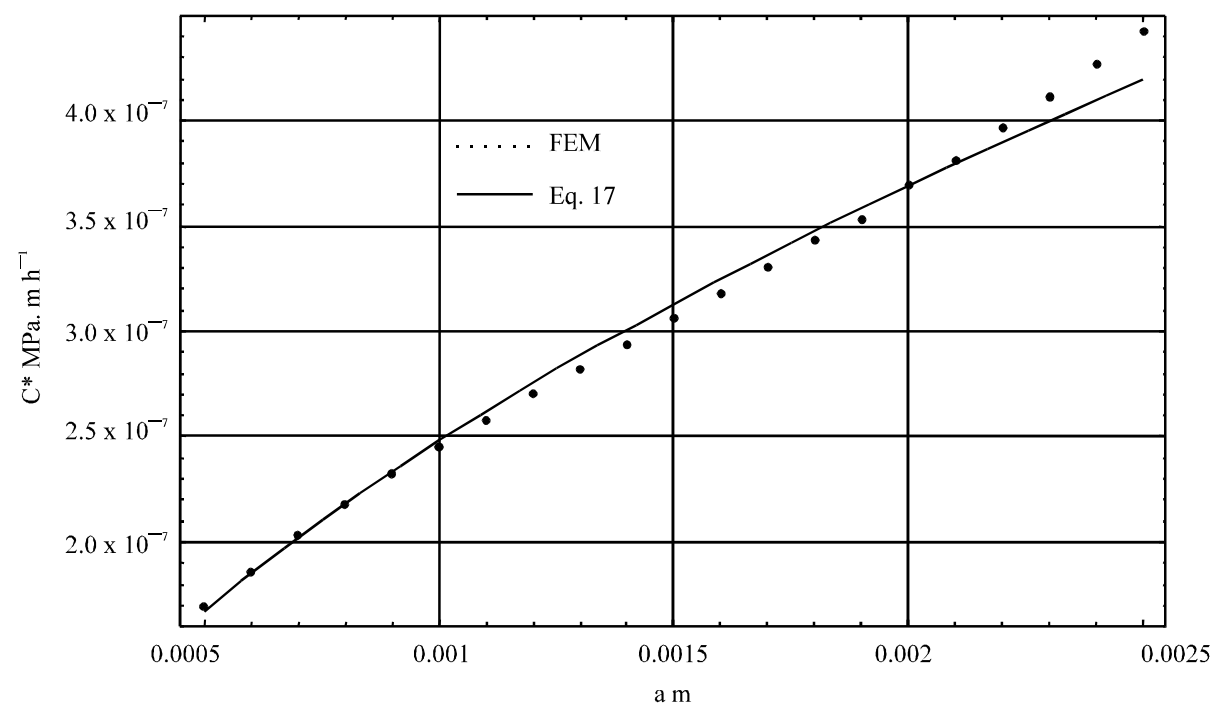

Fig. 9: Variation in $\mathrm{C}^{*}$-integral with crack length for remote loading Geometry No. $5 \mathrm{~d}=60 \mathrm{~mm}, \mathrm{~T}=930^{\circ} \mathrm{C}, \sigma_{0}=$ $0.1 \mathrm{Mpa}$

Multiple coefficient of determination was found to be $\mathrm{R}^{2}=0.984$ for this equation.

In all the above cases multiple coefficient of determination were higher than 0.98 which suggests a high level of accuracy of fit between the prediction equation and finite element data.

The variation in $\mathrm{C}^{*}$ obtained from Eq. 17 and directly from the finite element results, with respect to crack length are plotted in Fig. 8 and 9 for loaded projection and remote loading condition respectively.
Comparison of $\mathbf{C}^{*}$-Integral values: It is recognized by present authors that the method of calculation $\mathrm{C}^{*}$ based on reference stress is not necessarily very accurate, but in comparison with other methods it is very fast and relatively reliable. the following equation can be employed for determining approximate estimate:

$$
\mathrm{C}^{*}=\sigma_{\mathrm{ref}} \dot{\varepsilon}_{\mathrm{ref}}^{\mathrm{c}}\left(\mathrm{K} / \sigma_{\mathrm{ref}}\right)^{2}
$$




\section{Journal Name}

Table 5: comparison of $\mathrm{C}^{*}$ values obtained from FEM and Reference Stress Method $\sigma_{0}=0.1 \mathrm{~d}=60 \mathrm{~mm}$

\begin{tabular}{lllcccc}
\hline Deviation & $\begin{array}{l}\text { Loading } \\
\text { condition }\end{array}$ & $\begin{array}{l}\text { Crack length } \\
\mathrm{a}(\mathrm{mm})\end{array}$ & $\begin{array}{l}\text { Temperature } \\
\left({ }^{\circ} \mathrm{C}\right)\end{array}$ & $\begin{array}{l}\mathrm{C}^{*}\left(\mathrm{Mpa} \cdot \mathrm{m} \mathrm{h}^{-1}\right) \\
(\mathrm{RSM})\end{array}$ & $\begin{array}{l}\mathrm{C}^{*}\left(\mathrm{Mpa}^{-1} \mathrm{~m} \mathrm{~h}^{-1}\right) \\
\text { Eq. } 17\end{array}$ & $\begin{array}{l}\text { Geometry }^{2} \\
\text { No. }\end{array}$ \\
\hline $13 \%$ & Projection & 2 & 1150 & $2.479 \times 10^{-3}$ & $2.194 \times 10^{-3}$ & 1 \\
$9 \%$ & Projection & 0.5 & 930 & $8.482 \times 10^{-6}$ & $7.74 \times 10^{-6}$ & 3 \\
$18 \%$ & Projection & 2.5 & 650 & $2.742 \times 10^{-5}$ & $2.328 \times 10^{-5}$ & 5 \\
$15 \%$ & Remote & 1.5 & 930 & $2.278 \times 10^{-6}$ & $1.984 \times 10^{-6}$ & 3 \\
$5 / 16 \%$ & Remote & 1.2 & 1150 & $2.794 \times 10^{-2}$ & $2.398 \times 10^{-2}$ & 4 \\
$14 \%$ & Remote & 0.8 & 650 & $2.747 \times 10^{-6}$ & $2.41 \times 10^{-6}$ & 5 \\
\hline
\end{tabular}

Where $\dot{\varepsilon}_{\text {ref }}^{c}$ is the total rate of strain obtained from the material stress-strain properties at the reference stress and $\mathrm{K}$ is stress intensity factor and $\sigma_{\text {ref }}$ is reference stress and it can be determined from limit analysis or numerical methods ${ }^{[15,16]}$. When limit analysis is employed, for a component subjected to a load P, the reference stress it is given by:

$$
\sigma_{\text {ref }}=\sigma_{y} \frac{P}{P_{L C}}
$$

Where $\sigma_{\mathrm{y}}$ is the material yield stress and $\mathrm{P}_{\mathrm{LC}}$ the corresponding collapse load of the cracked component that have been obtained by FEM. The relationship between strain rate and stress is as follow:Z

$$
\dot{\varepsilon}_{\text {ref }}^{\mathrm{c}}=A \sigma_{\text {ref }}^{\mathrm{n}}
$$

The results were compared for six different components that are shown in Table 5. It is seen that the agreement between two approaches is reasonably good. As it is seen, the RSM is a simplified method so the results obtained from this method are an over estimate.

\section{TRANSITION TIME}

Riedel and Rice in their original analyses presented a concept of transition time, $T_{t}$ They defined the transition time as the time when the small-scale-creep stress fields equal the extensive steady-state creep fields characterized by $\mathrm{C}^{*}$.

In order to make sure that transition time has passed, finite element analyses have been done for 1000 hours. Nonetheless, to examine the accuracy of this time, the results in different times were examined and as was expected, it did not change after a certain time long before $1000 \mathrm{~h}$. Figure 10 and 11 shows the transition time for different components and loading conditions.

In order to show all the results in one graph the vertical axis is normalized by $C^{*}$ (i.e., the final constant answer) and the horizontal axis are normalized by transition time. As it is seen components that have a higher stress concentration factor, passes transition time

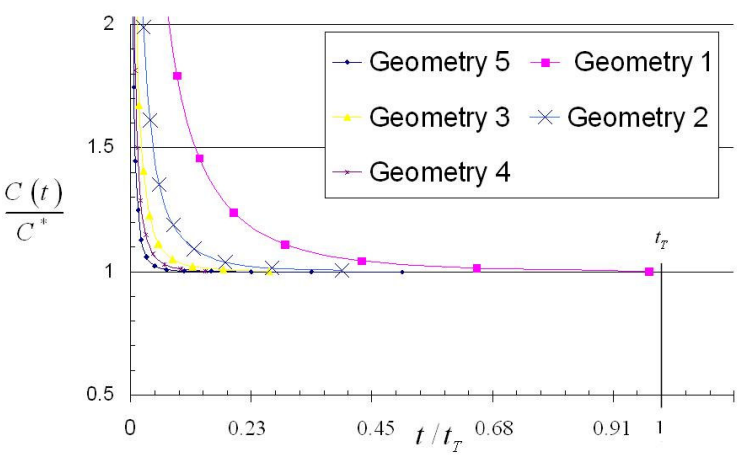

Fig. 10: The variation of normalized $\mathrm{C}(\mathrm{t})$ integral with respect to normalized time for loaded projection condition and for $\mathrm{a}=0.5 \mathrm{~mm}, \mathrm{p}=$ $0.1 \mathrm{Mpa}, \mathrm{T}=650^{\circ} \mathrm{C}$

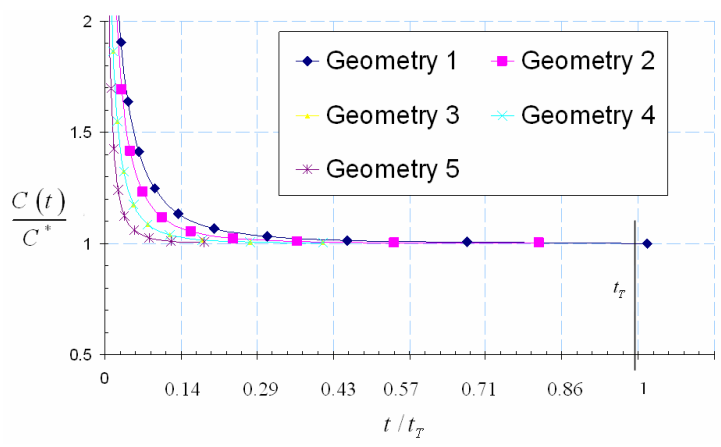

Fig. 11: The variation of normalized $\mathrm{C}(\mathrm{t})$ integral with respect to normalized time for $\mathrm{r}$ condition and for $\mathrm{a}=0.5 \mathrm{~mm}, \mathrm{p}=0.1 \mathrm{Mpa}, \mathrm{T}=650^{\circ} \mathrm{C}$

faster than components with lower stress concentration factor and components subjected to projection loading, have shorter transition time than components subjected to remote loading.

\section{CREEP ZONE SIZE}

Riedel and Rice ${ }^{[17]}$ arbitrarily defined the creep zone boundary as the locus of points where timedependent effective creep strains equal the instantaneous effective elastic strains in the cracked body. 


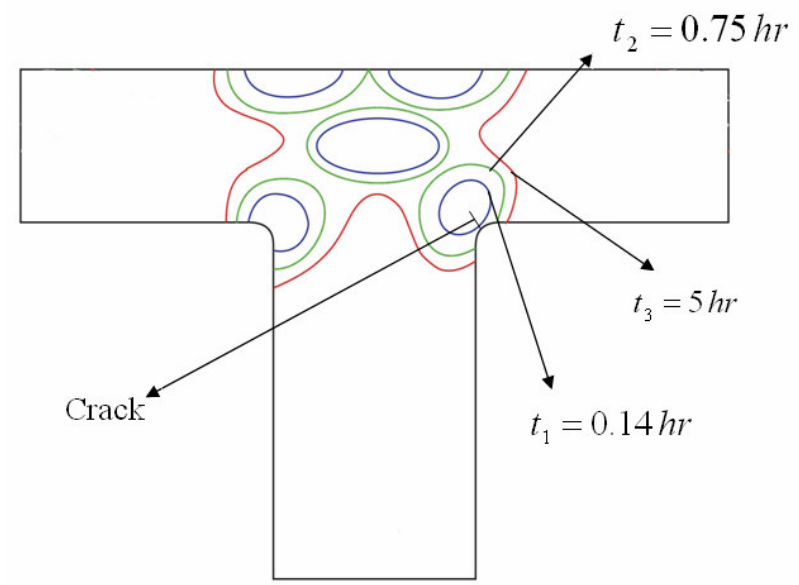

Fig. 12: A typical creep zone growth in component subjected to projection loading

Generally, the creep zone starts at some points with high stress concentration factor and growths to cover all the body. For a components subjected to projection loading the creep zone growth is shown in three steps in Fig. 12. It is seen that the creep zone starts at five high stress points (i.e. crack tip, fillets, etc) that have maximum stress concentration in the body, then it covers all of the body.

For component subjected to remote loading the creep zone growth is shown in four steps in Fig. 13. It is clear that the creep zone starts at the fillets and then it carries on in to the flat part. The creep zone covers the projection part in two steps.

\section{VARIATION IN C* WITH THE RATIO h/d}

The value of $\mathrm{C}^{*}$-Integral decreases with increase in ratio of $\mathrm{h} / \mathrm{d}$. up to a specific point after which any increase of $h / d$ does not have any effect in $C^{*}$ values. In fact, this point is a threshold point. Actually, a designer should consider that after threshold point just the weight and volume of the component increase and it dose not help to decrease the $\mathrm{C}^{*}$ values. Variation in $\mathrm{C}^{*}$ with the ratio h/d is shown in Fig. 14. As it can be seen in the range of $0.5 \leq \mathrm{h} / \mathrm{d} \leq 1$ this ratio has a high effect on $\mathrm{C}^{*}$ values. However, in the range of $1<\mathrm{h} / \mathrm{d} \leq 2$ variation of $\mathrm{h} / \mathrm{d}$ has a low effect on $\mathrm{C}^{*}$ values which is the best range for designing a component. Finally, the point of $\mathrm{h} / \mathrm{d}=3$ is the threshold point.

\section{VARIATION IN Q* WITH $K_{t}$}

Knowledge of how $\mathrm{Q}^{*}$ varies with $\mathrm{K}_{\mathrm{t}}$ can help the designer to choose the best geometry. This variation is shown in Fig. 15-17 for projection loading.

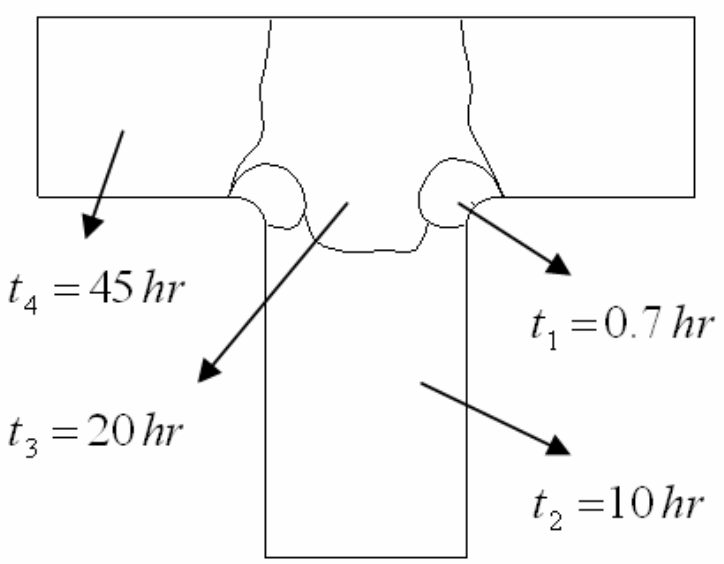

Fig. 13: A typical Creep zone growth in component subjected to remote loading

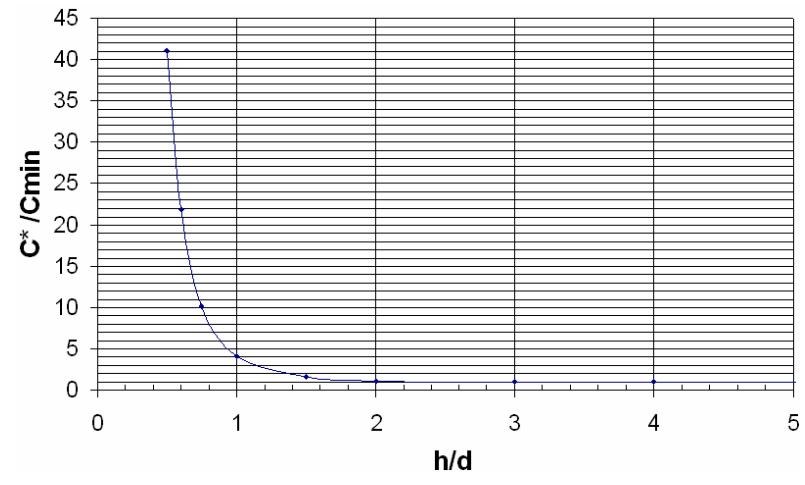

Fig. 14: Variation in $\mathrm{C}^{*}$ with the ratio $\mathrm{h} / \mathrm{d}$ for component subjected to projection loading $\mathrm{p}=$ $0.1 \mathrm{Mpa}, \mathrm{k}_{\mathrm{t}}=16.69, \mathrm{~T}=1150^{\circ} \mathrm{C}, \mathrm{a}=0.5 \mathrm{~mm}$

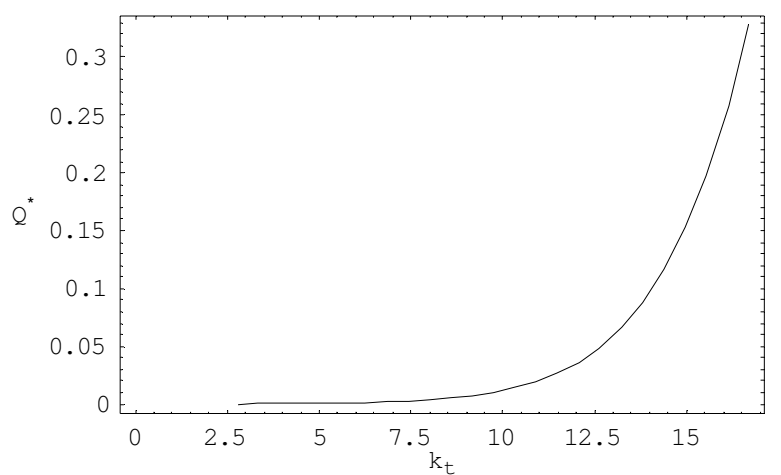

Fig. 15: Variation of $\mathrm{Q}^{*}$ with $\mathrm{K}_{\mathrm{t}}$ in loaded projection condition for $\mathrm{a} / \mathrm{d}=0.042, \mathrm{n}=2.54$

It is seen in Fig. 15 and 16 (i.e., 650 and $930^{\circ} \mathrm{C}$ ) in range of $2.5 \leq \mathrm{k}_{\mathrm{t}} \leq 10$ increase of $\mathrm{K}_{\mathrm{t}}$ has a small effect on 
$\mathrm{Q}^{*}$ value and is the best range for design. However, after point $\mathrm{K}_{\mathrm{t}}=12$ the designer should be careful

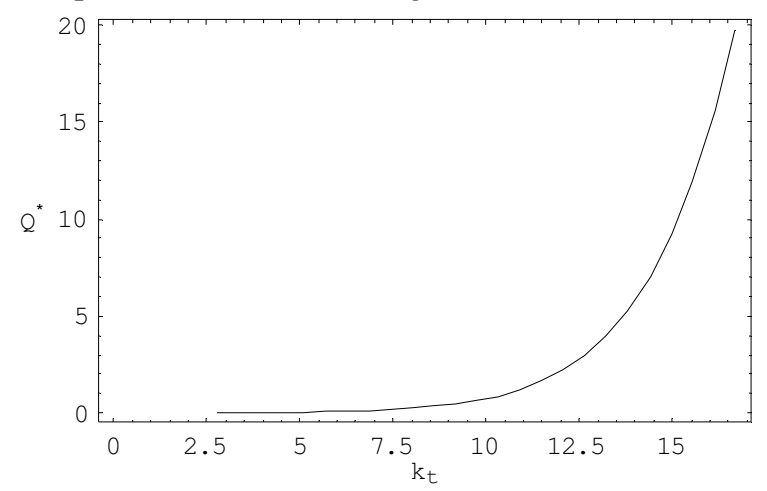

Fig. 16: Variation of $\mathrm{Q}^{*}$ with $\mathrm{K}_{\mathrm{t}}$ in loaded projection condition for $\mathrm{a} / \mathrm{d}=0.42, \mathrm{n}=4.6$

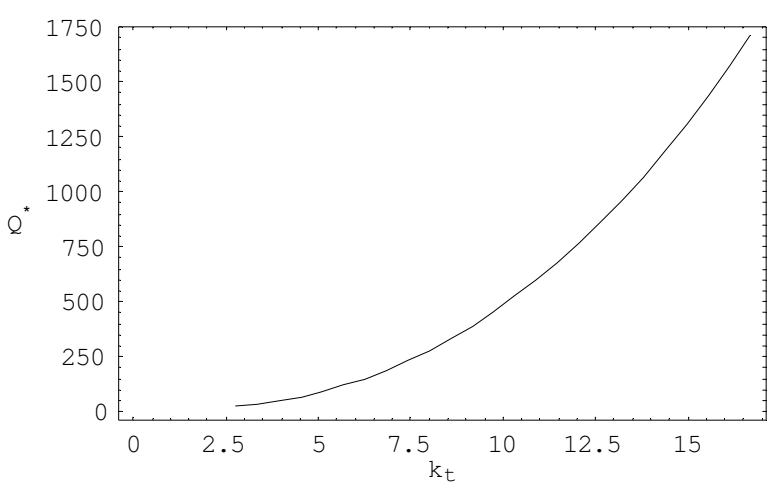

Fig. 17: Variation of $\mathrm{Q}^{*}$ with $\mathrm{K}_{\mathrm{t}}$ in loaded projection condition for $\mathrm{a} / \mathrm{d}=0.042, \mathrm{n}=1.43$

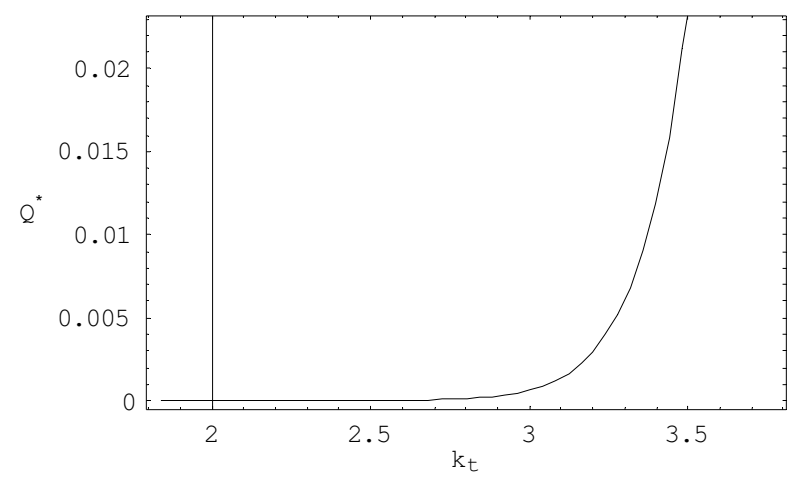

Fig. 18: Variation of $Q^{*}$ with $\mathrm{K}_{\mathrm{t}}$ in remote loading condition. $\mathrm{a} / \mathrm{d}=0.042, \mathrm{n}=2.54$

because $Q^{*}$ values growth rapidly. It is clear that the behavior of $\mathrm{Q}^{*}$ with variation of $\mathrm{K}_{\mathrm{t}}$ in temperatures 650 and $930^{\circ} \mathrm{C}$ are relatively the same. It is predictable that behavior of $\mathrm{Q}^{*}$ between these two temperatures is similar.

Variation in $\mathrm{Q}^{*}$ with $\mathrm{K}_{\mathrm{t}}$ is shown in Fig. 18-20 for remote loading. It is seen in all temperatures in the

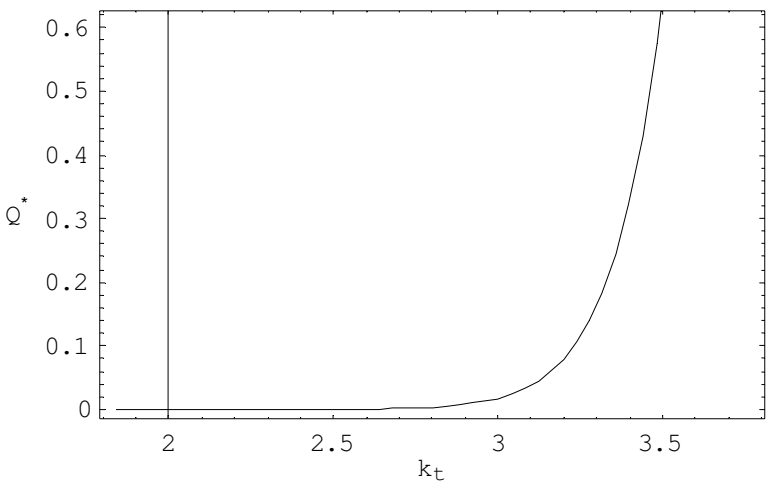

Fig. 19: Variation of $Q^{*}$ with $K_{t}$ in remote loading condition. $\mathrm{a} / \mathrm{d}=0.042, \mathrm{n}=4.6$

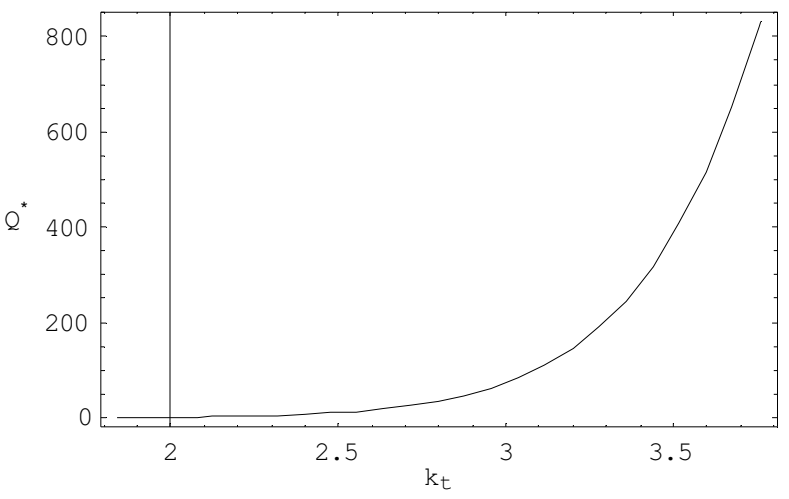

Fig. 20: Variation of $\mathrm{Q}^{*}$ with $\mathrm{K}_{\mathrm{t}}$ in remote loading condition. $\mathrm{a} / \mathrm{d}=0.042, \mathrm{n}=1.43$

range of $1.84 \leq \mathrm{k}_{\mathrm{t}} \leq 3$ increasing $\mathrm{K}_{\mathrm{t}}$ has a small effect on $\mathrm{Q}^{*}$ value and is the best range for design. However, after point $\mathrm{K}_{\mathrm{t}}=3$ the designer should be careful because $\mathrm{Q}^{*}$ values growth rapidly. The behavior of $\mathrm{Q}^{*}$ with variation of $K_{t}$ in three temperatures are relatively the same, it is predictable that behavior of $\mathrm{Q}^{*}$ between these three temperatures is similar.

\section{CONCLUSIONS}

- $\mathrm{C}^{*}$-Integral values for components with loaded projection can be significantly higher than the corresponding values for remote loading.

- Projection length, $\mathrm{h}$, in remote loading condition does not have any important effect on $\mathrm{C}^{*}$-Integral values. 
- Smaller fillet radius, $r$ and projection length, $h$, cause higher $\mathrm{C}^{*}$.

- Variation of crack direction, a, in range $20<\mathrm{a}<90$ compare with maximum value of $\mathrm{C}^{*}$, cause an error around $30 \%$ in $\mathrm{C}^{*}$.

- The relation between $\mathrm{C}^{*}$ and nominal stress $\sigma_{0}$ had been determined as $\mathrm{C}^{*} \propto \sigma_{0}^{\mathrm{n}+1}$.

- Higher stress concentration factor in component cause smaller transient time.

- The point $\mathrm{h} / \mathrm{d}=3$ is the threshold point, after this point an increase in the ratio $\mathrm{h} / \mathrm{d}$ does not effect $\mathrm{C}^{*}$ value.

- The creep zone starts at some points with high stress concentration factor and growths to cover all the body.

- In almost all cases the first $3 / 4$ of determination range of $K_{t}$ is useful for designing $\mathrm{T}$-section component.

\section{REFERENCES}

1. Hertzberg, R.W., 1976. Deformation and Fracture Mechanics of Engineering Materials. John Wiley, New York.

2. Paris, P.C. and G. Sih, 1965. Fracture toughness testing and its application. In: ASTM STP 381, American Society for Testing and Materials, Philadelphia, Pennsy1-vania, pp: 30-81.

3. Harris, D.O. 1967. Stress intensity factor for hollow circumferentially notch round bars. J. Basic Eng., 89: 49-54.

4. Hellen, T.K., 1975. On the method of virtual crack extensions. Int. J. Numer. Meth. Eng., 9: 187-207.

5. Gowhari-Anaraki, A.R., S.J. Hardy and R. Adibi-Asl, 2003. Mixed-mode fatigue crack propagation in thinT-sections under plane stress. J. Strain Anal. 38: 557-575.

6. Biglaria, F., K.M. Nikbin, I.W. Goodall and G.A. Webster, 2003. Determination of fracture mechanics parameters $\mathrm{J}$ and $\mathrm{C}^{*}$ by finite element and reference stress methods for a semi-elliptical flaw in a plate. Int. J. Pressure Vessels and Piping, 80: 565-571.
7. Kim, Y.J. and D.J. Shim, 2005. Relevance of plastic limit loads to reference stress approach for surface cracked cylinder problems. Int. J. Pressure Vessels Piping, 82: 687-699.

8. Assire, A., B. Michel and M. Raous, 2001. Creep crack initiation and creep crack growth assessments in welded structures. Nuclear Eng. Design, 206: 45-56.

9. Mendnhall, W., J.E. Reinmuth and R. Beaver, 1989. Statistics for Management and Economics. 6th Edn., (PWS-kent Publishing Company, Boston, Massachusetts).

10. Engineering Sciences Data Unit, data sheet 69020.

11. BS 5447 Methods of Test for Plane Strain Fracture Toughness $\left(\mathrm{K}_{\mathrm{IC}}\right)$ of Metallic Material 1977 (British Standards Institution, London).

12. ABAQUS Users manual, version 6.6-1, Inc. 2006.

13. Landes, J.D. and J.A. Begley, 1976. A fracture mechanics approach to creep crack growth. In: Mechanics of Crack Growth, ASTM STP 590. Am. Soc. Testing Mat., pp: 128-148.

14. Saxena, A., 1998. Nonlinear Fracture Mechanics for Engineers. 1.Fracture mechanics 2.Nonlinear Fracture.

15. Webster, G.A. and R.A. Ainsworth, 1994. High temperature component life assessment. London: Chapman and Hall.

16. Sim, R.G., 1971. Evaluation of reference parameters for structures subjected to creep. J. Mech. Eng. Sci., 13: 47-50.

17. Riedel, H. and J.R. Rice, 1980. Tensile cracks in creeping solids. Fracture Mecahnics: 12th Conference, ASTM STP 700, Am. Soc. Testing Mat., Philadlphis, pp: 112-130. 